\title{
Sirenomelia, the mermaid baby: a case report
}

\section{Reetika Joshi $^{1 *}$, Veino Kuveio Duomai ${ }^{1}$, Bianchi Sangma ${ }^{2}$}

${ }^{1}$ Department of Obstetrics and Gynaecology, ${ }^{2}$ Department of Paediatrics, Baptist Christian Hospital, Tezpur, Assam, India

Received: 14 September 2019

Accepted: 05 October 2019

\section{*Correspondence:}

Dr. Reetika Joshi,

E-mail: deepak.ji.joshi@gmail.com

Copyright: () the author(s), publisher and licensee Medip Academy. This is an open-access article distributed under the terms of the Creative Commons Attribution Non-Commercial License, which permits unrestricted non-commercial use, distribution, and reproduction in any medium, provided the original work is properly cited.

\begin{abstract}
Sirenomelia sequence or mermaid syndrome is a rare congenital structural anomaly characterized by different degrees of fusion of lower limbs, thoracolumbar spinal anomalies, sacrococcygeal agenesis, genitourinary and anorectal atresia. The incidence of sirenomelia is $0.8-1$ cases/ $10^{5}$ births with male to female ratio being $3: 1$. A malformations patient with 40 weeks of gestation admitted with complaints of decreased fetal movements for one week. An emergency C-section was done in view of term pregnancy with severe oligohydramnios and intrauterine growth restriction with poor bishop's score. A $1.9 \mathrm{~kg}$ live baby with fused lower limbs was delivered. The new born baby had narrow chest, fused both lower limbs and feet with 11 toes, small rudimentary external genitalia, imperforate anus and single umbilical artery. The baby also had features of potter's facies including low set large ears, receding chin and prominent infraorbital folds. Sirenomelia is a rare fatal congenital anomaly. Early detection by prenatal ultrasound will help in timely termination of pregnancy.
\end{abstract}

Keywords: Fusion of lower limbs, Mermaid syndrome, Potters facies, Sirenomelia

\section{INTRODUCTION}

Sirenomelia sequence or Mermaid syndrome is a rare congenital structural anomaly characterized by different degrees of fusion of lower limbs, thoracolumbar spinal anomalies, sacrococcygeal agenesis, genitourinary malformations and anorectal atresia. ${ }^{1}$ It is described as the most severe form of caudal regression syndrome. ${ }^{2}$ The first medical reference of sirenomelia was made in sixteenth century by Rocheus and Palfyn. ${ }^{3}$ The incidence of sirenomelia $0.8-1$ case $/ 10^{5}$ with male to female ratio, $3: 1{ }^{4}$ There is strong association to maternal diabetes where relative risk is $1: 200-250.5$

\section{CASE REPORT}

A 25-year-old G2 A1 with 40 weeks of gestation was admitted with decreased fetal movements and not in labor. She had a previous history of intrauterine fetal demise at 6 months. No obvious gross congenital abnormalities were noted in previous pregnancy. She was registered at primary health centre and belonged to a tribal community. She had only two antenatal visits at the health centre.There was history of betel nut intake both before and during pregnancy. She missed oral glucose tolerance test, thyroid function test, targeted imaging for foetal anomalies scan and screening for chromosomal abnormalities. An ultrasound scan on day of admission showed single live fetus in vertex presentation, estimated gestational age 34 weeks, estimated fetal weight $2.3 \mathrm{~kg}$, severe oligohydramnios and intrauterine growth restriction. Patient was taken up for emergency $\mathrm{C}$ section in view of term pregnancy with severe oligohydramnios and intrauterine growth restriction with poor bishop's score. A $1.9 \mathrm{~kg}$ live baby with fused lower limbs delivered (Figure 1).

The baby had a weak cry at birth. A minimal amount of amniotic fluid was drained at the time of delivery. The new born had gross anomalies like fused both lower 
limbs and feet with 11 toes, rudimentary genitalia, imperforate anus, narrow chest and single umbilical artery (Figure 2). The baby had potters' facies receding chin, prominent infraorbital fold and low set large ears (Figure 3).

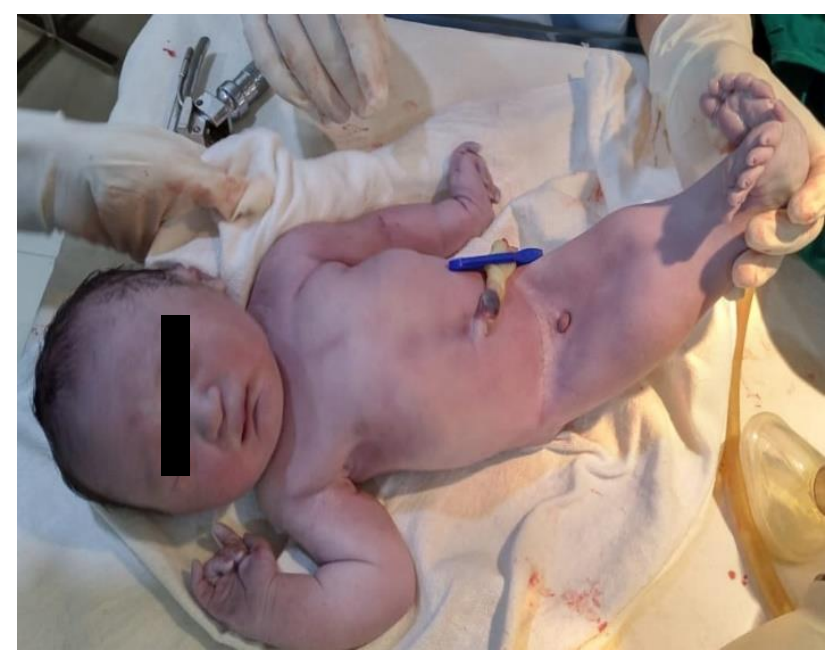

Figure 1: The complete picture of the sirenomelic baby.

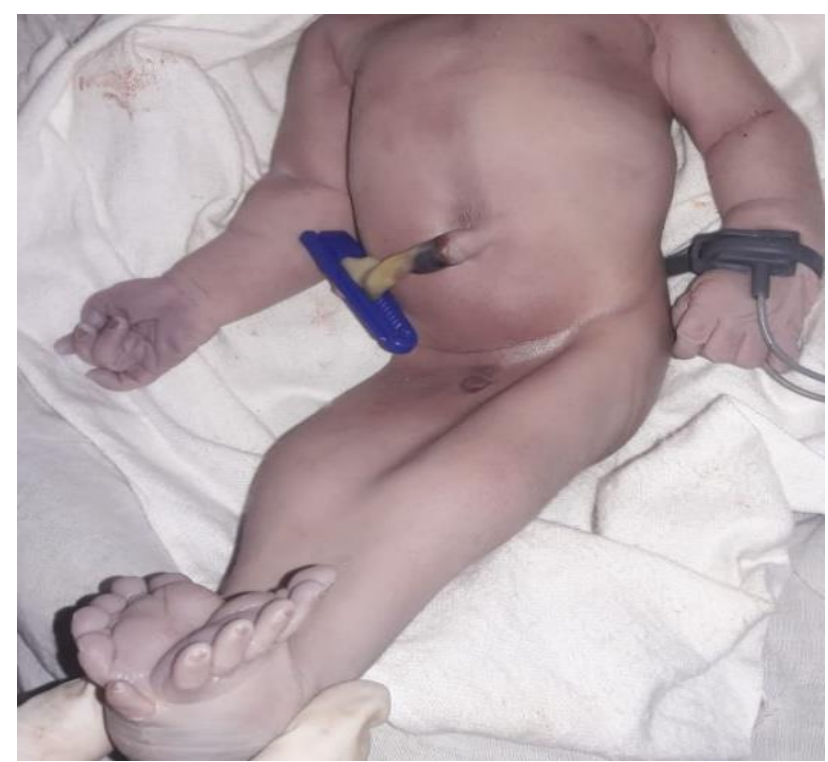

Figure 2: Narrow chest, rudimentary genitalia, fused legs, 11 toes.

The baby was shifted to NICU and expired 10 hours post birth due to respiratory distress. Autopsy and investigation were denied by parents. Postpartum period was uneventful for the patient. Patient had normal sugar profile in postpartum period. She was found to have subclinical hypothyroidism.

\section{DISCUSSION}

Sirenomelia is a rare congenital anomaly. Approximately 300 cases have been reported in the world literature so far of which 14 have been reported in India. ${ }^{6}$ Most of the affected newborns are either still born or expire soon after birth. There have been nine reported sirenomelia affected cases, who have survived after multiple reconstructive surgeries. ${ }^{7}$ The most important factor for survival of affected newborns was functional kidney.

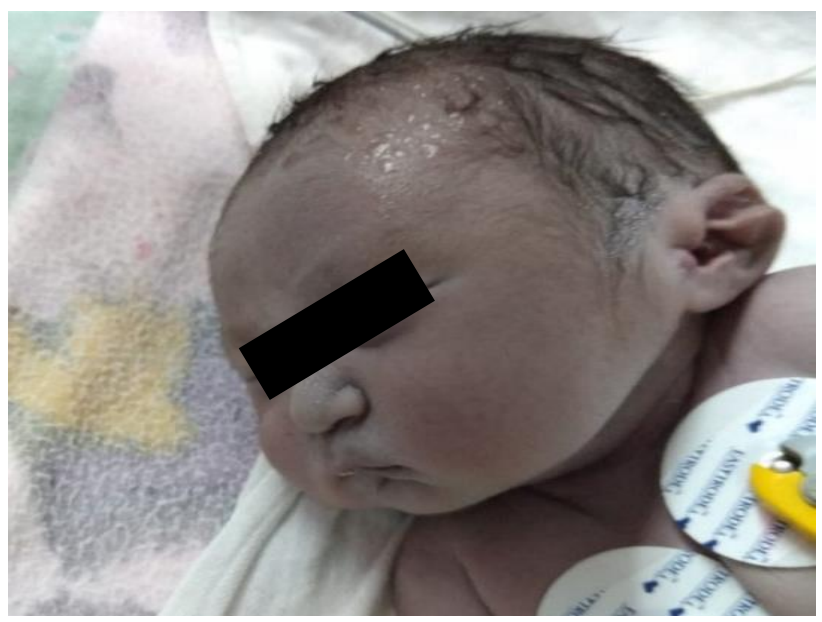

Figure 3: Potter's facies, prominent infraorbital folds, slit like mouth, receding chin and low set soft dysplastic ears.

The precise aetiology of sirenomelia sequence remains unclear. The two main pathologic hypothesis namely, the vascular steal hypothesis and defective blastogenesis hypothesis are proposed.

According to vascular steal hypothesis, fusion of limbs results from a deficient blood flow and nutrient supply to the caudal mesoderm, which results in agenesis of midline structures and subsequent fusion of both lower limbs. ${ }^{8}$

As per defective blastogenesis, the primary defect in the development of caudal mesoderm is attributed to teratogenic event during the gastrulation stage. It then interferes with the formation of notochord resulting in abnormal development of caudal region. ${ }^{9}$ Tobacco use, vitamin A, maternal diabetes and heavy metal exposure are possible causative factors. ${ }^{10}$

The fusion of lower extremities, presence of single umbilical and persistent vitelline artery are major features of sirenomelia. The facial abnormality in mermaid syndrome is known as potter's facies which includes large, low set ears, prominent epicanthic folds, hypertelorism, flat nose and receding chin. When potters facies are present along oligohydramnios and pulmonary hypoplasia, it is known as Potter's syndrome. ${ }^{11}$

\section{Sirenomelia has been classified into three types ${ }^{12}$}

Sirenomelia : $\quad$ There are no feet and toes, legs 


$\begin{array}{ll}\text { Apus } & \begin{array}{l}\text { are conjoined fully and single } \\ \text { femur and tibia are seen }\end{array} \\ \text { Sirenomelia } & : \quad \begin{array}{l}\text { There is a foot but two femur, } \\ \text { two tibia and two fibular bones } \\ \text { Unipus }\end{array} \\ \text { seen }\end{array}$

Stocker and Heifetz classified sirenomelia infants from Type I to Type VII according to the presence or absence of bones in the lower limbs. ${ }^{13}$

- Femur and tibia bones are formed

- Only a fibula bone seen

- No fibula bone

- The two femur and two fibula bones are conjoined imperfectly

- The two femur bones are conjoined imperfectly

- Only a femur and a tibia can be seen

- Only a femur can be seen and there is no tibia.

In most of the cases the diagnosis of sirenomelia was made after birth. In antenatal period, it can be diagnosed as early as 13 weeks by using high resolution or color doppler sonography. ${ }^{14}$

Prenatal diagnosis of sirenomelia can be made by presence of fused bilateral femur, decreased distance between two femurs and decreased or absent mobility of the two lower limbs with respect to each other. ${ }^{15}$ In addition spinal, genitourinary and anorectal anomalies can be seen on sonography.

\section{CONCLUSION}

Sirenomelia is one of the rarest and lethal congenital anomaly. When diagnosed antenatally, termination should be offered. Regular antenatal check-up with optimum maternal blood glucose level in preconceptional period and prevention of exposure to teratogenic agents. An early scan between 11-13 weeks can help pick up the anomaly. So, the termination of pregnancy can be planned at the earliest.

\section{ACKNOWLEDGEMENT}

Authors would like to thank the Department of Obstetrics and Gynaecology at Baptist Christian Hospital, Tezpur, Assam for their support and cooperation of patients and their families admitted to this hospital.

Funding: No funding sources Conflict of interest: None declared Ethical approval: Not required

\section{REFERENCES}

1. Valenzano M, Paoletti R, Rossi A, Farinini D, Garlaschi G, Fulcheri E. Sirenomelia. Pathological features, antenatal ultrasonographic clues, and a review of current embryogenic theories. Hum Reprod Update. 1999;5:82-6.

2. Duhamel B. From the mermaid to anal imperforation: the syndrome of caudal regression. Arch Dis Child. 1961;36(186):152-5.

3. Van Kerisblick J, Cannie M, Robrechts C. First trimester diagnosis of Sirenomelia, Prenat Diagn. 2006;26:684-8.

4. Reddy KR, Srinivas S, Kumar S, Reddy S, Hariprasad Irfan GM. Sirenomelia a rare presentation. J Neonatal Surg. 2012;1:7.

5. Aslan H, Yanik H, Celikaslan N, Yildirim G, Ceylan Y. Prenatal diagnosis of caudal regression syndrome: a case report. BMC Preg Childbirth. 2001;1:8.

6. Duhamel B. From the mermaid to anal imperforation: the syndrome of caudal regression. Arch Dis Child. 1961;36:152-5.

7. Romano S, Esposito V, Fonda C, Russo A, Grassi R. Beyond the myth: the mermaid syndrome from homeus to andersen a tribute to hans Christiam Anderson's biecentennial of birth. Eur J Radiol. 2006;58:252-9.

8. Sadler TW, Rasmussen SA. Examining the evidence for vascular pathogenesis of selected birth defects. Am J Med Genet A. 2010;152A:2426-36.

9. Duesterhoeft SM, Ernst LM, Siebert JR, Kapur RP. Five cases of caudal regression with an aberrant abdominal umbilical artery: Further support for a caudal regression sirenomelia spectrum. Am J Med Genet A. 2007;143a:3175-84.

10. Naveena S, Mrudula C. Sirenomelia: the mermaid syndrome: a case report. IOSR J Dent Med Sci. 2013;7:1-4.

11. Dharmraj M, Gaur S. Sirenomelia: a rare case of foetal congenital anomaly. J Clin Neonatol. 2012;1:221-3.

12. Khan A, Ismail F, Werke I, Mermaid Baby GH. irenomelia: Case Report and Review of the Literature. SA J Radiol. 2010;14:66-8.

13. Stocker JT, Heifitz SA. Sirenomelia. A morphological study of 33 cases and review of the literature. Perspect Pediatr Pathol. 1987;10:7-50.

14. Vijayaraghavan SB, Amudha AP. High resolution sonographic diagnosis of sirenomelia. J Ultrasound Med. 2006;25:255-7.

15. Taori KB, Mitra K, Ghonga NP, Gandhi RO, Mammen T, Sahu J. Musculoskeletal Imaging. Indian J Radiol Imag. 2002;12(3):399-401.

Cite this article as: Joshi R, Duomai VK, Sangma B. Sirenomelia, the mermaid baby: a case report. Int J Reprod Contracept Obstet Gynecol 2019;8:460911. 